\title{
Splay fault and megathrust earthquake slip in the Nankai Trough
}

\author{
Phil R. Cummins, Takane Hori, and Yoshiyuki Kaneda
}

Frontier Research Program for Subduction Dynamics, Japan Marine Science and Technology Center, 2-15 Natsushima-cho, Yokosuka, Japan

(Received August 13, 1999; Revised September 11, 2000; Accepted September 11, 2000)

\begin{abstract}
We consider whether splay fault slip may be a factor influencing the behavior of megathrust earthquakes in the Nankai Trough. Consideration of tsunami inversion results from other studies indicates that slip on one or more splay faults may be particularly important for the segment of the Nankai Trough offshore western Shikoku. These results suggest that during at least two megathrust earthquakes substantial slip may have occurred on one or more splay faults which cut the island arc crust over $100 \mathrm{~km}$ landward of the trench axis. In contrast to smaller subsidiary thrusts in the semi-consolidated and unconsolidated sediments very near the trough axis, the crustal faults considered here could accumulate and release considerable tectonic stress. Through a simple finite element calculation we demonstrate that slip on such faults can release some of the shear stress on the megathrust accumulated through plate subduction, and therefore may have some influence on the behavior of megathrust earthquakes.
\end{abstract}

\section{Introduction}

Subduction of the Philippine Sea plate beneath southwestern Japan has been the cause of repeated great interplate earthquakes there whose history can be traced back for over one thousand years. This history shows that while earthquakes show some repeatability, there is also considerable variation, with different earthquakes rupturing different segments of the Nankai Trough at intervals from roughly 100 to over 200 years (Ando, 1975). Also, the size of earthquakes varies considerably, with some earthquakes rupturing almost the entire $1000 \mathrm{~km}$ length of the Nankai Trough from Suruga Bay to Kyushu, while others rupture only isolated segments of roughly $200 \mathrm{~km}$ length.

McCaffrey (1993) suggested that the maximum size of subduction zone earthquakes is limited by anelastic deformation of the overriding plate. By comparing earthquake slip vectors with plate convergence vectors, he was able to estimate the amount of convergence accommodated by anelastic deformation. High anelastic deformation in the upper plate limits its ability to store elastic energy, which in turn limits the maximum size of interplate earthquakes.

Here, we consider whether a similar role may be played by splay faults, which are parallel to the plate boundary at depth but "splay" off it, becoming steeper as they approach the surface. There has been speculation that slip on such faults occurs during subduction zone earthquakes, but the only direct observation has been that of Plafker (1972), who observed $8 \mathrm{~m}$ of thrust displacement on Montague Island which was inferred to have occurred during the Alaskan earthquake of 1964. More recently, paleoseismic evidence has been found for sudden thrust displacement across faults in the accretionary complex of the south Cascadia subduction zone, which extends onland in northern California (Clarke

Copy right $(\mathcal{C}$ The Society of Geomagnetism and Earth, Planetary and Space Sciences (SGEPSS); The Seismological Society of Japan; The Volcanological Society of Japan; The Geodetic Society of Japan; The Japanese Society for Planetary Sciences. and Carver, 1992). Clarke and Carver (1992) suggest that the 3-5 $\mathrm{m}$ of displacement for each event occurred as a part of larger megathrust earthquakes, but also that such thrusting did not occur for every megathrust event.

We speculate that such splay faults may also act to limit the rupture to the landward portion of the plate boundary. One mechanism by which they might do so is via slip partitioning, so that a given amount of slip on the down-dip portion of the plate boundary might be apportioned into splay fault + plate boundary slip on the up-dip portion. In what follows we will suggest that this has in fact occurred during previous earthquakes in the Nankai Trough by an examination of tsunami modeling results obtained in other studies. Finally, we show that the stress perturbation on the megathrust due to splay fault slip acts to reduce slip on the up-dip portion of the plate boundary, which should lead to reduced earthquake slip there.

\section{Splay Faults in the Nankai Trough}

Sugiyama (1994) describes in considerable detail the "seismic deformation area" in the forearc basin/outer ridge areas of the Nankai Trough. The geologic deformation described by Sugiyama (1994) is permanent, being the cumulative result of deformation associated with interplate earthquakes. He specifically excludes from consideration cyclic deformation, i.e., coseismic deformation that is recovered during the interseismic period. This zone of permanent earthquake related deformation terminates at the uppermost inner trench slope, at a series of landward-dipping faults which Kagami et al. (1983) characterize as seismogenic. In this paper we suggest that the dip of some of these faults may shallow with increasing depth and merge with the plate boundary, as indicated in Fig. 2(a), and that they may influence the accumulation and release of stress along the plate boundary itself.

That slip on such faults actually occurs during great interplate earthquakes in the Nankai Trough is suggested by a con- 

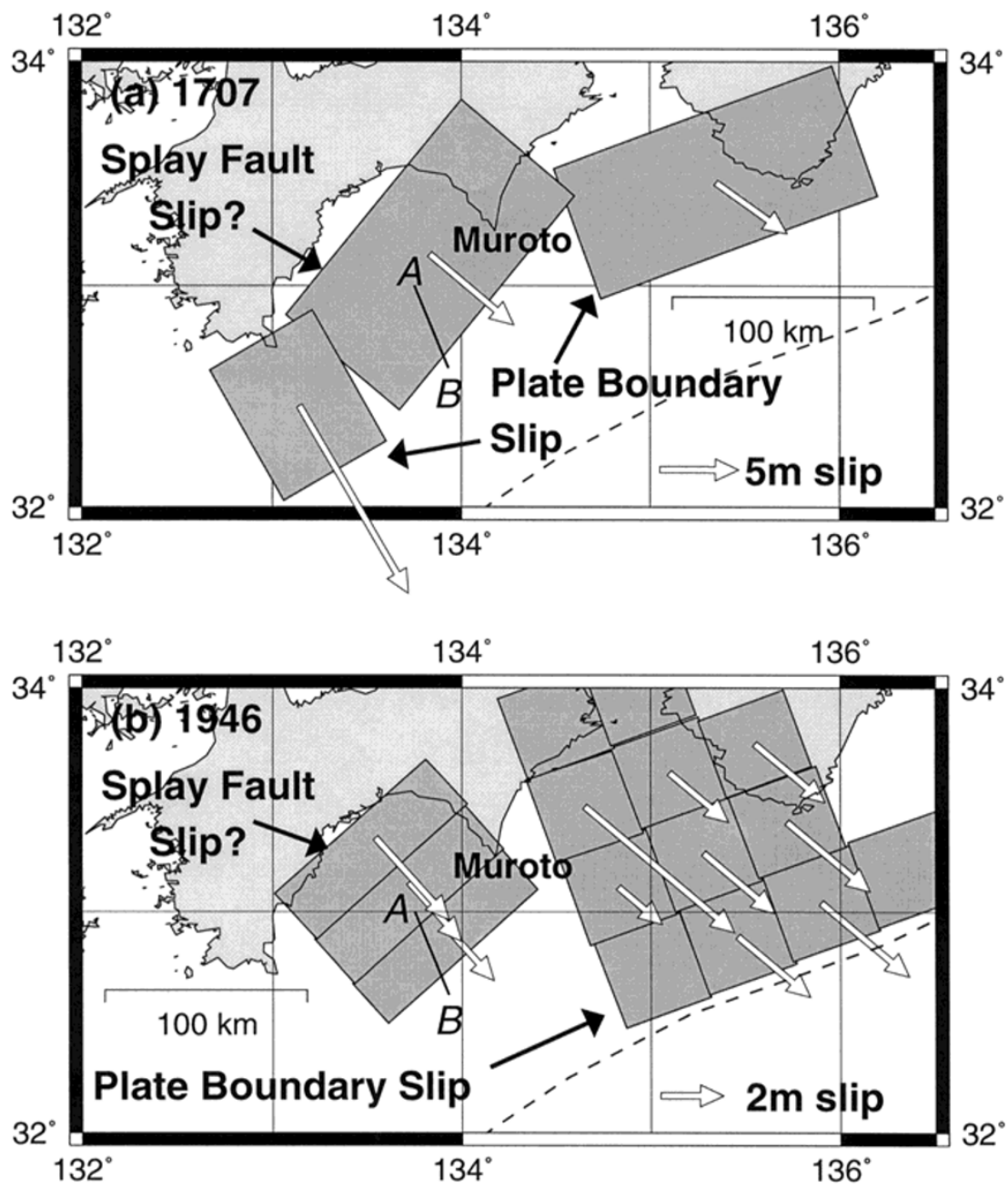

Fig. 1. (a) The fault slip model for the 1707 Hoei earthquake obtained by Aida (1981) from tsunami modeling. (b) The fault slip model for the 1946 Nankai earthquake inferred by Cummins and Kaneda (2000), which was modified from Tanioka and Satake (2001). The line A-B refers to the multichannel seismic section in Fig. 2(b).

sideration of results from studies of tsunamis generated by such megathrust events. In Fig. 1(a), we show the preferred fault slip model which Aida (1981) obtained by modeling crustal deformation and tsunami run-up heights for the 1707 Hoei earthquake. This consists of three separate sub-faults, the westernmost and easternmost of which are oriented with strike parallel to the axis of the Nankai Trough, while the central sub-fault is inclined more northward. As a result of the different character of the central fault, the largest coseismic surface displacement occurs near Cape Muroto, almost $100 \mathrm{~km}$ from the trough axis.

A remarkably similar model for the 1946 Nankai earthquake was suggested by Cummins and Kaneda (2000), who re-examined the results of the tsunami and geodetic inversions of Tanioka and Satake (2001) and Sagiya and Thatcher (1999), respectively. They concluded that the crustal displacement in the western part of the Nankai Trough inferred by these studies can in large part be explained by the fault model shown in Fig. 1(b). The western sub-fault of their model is very similar to the central sub-fault in Aida's (1981) model for the 1707 Hoei earthquake, with a similar strike and causing the largest coseismic surface displacement to occur almost $100 \mathrm{~km}$ from the trough axis.

A consideration of the main factors constraining Aida's (1981) model for the 1707 earthquake and that of Cummins and Kaneda (2000) for the 1946 earthquake suggests that they are similar: A volume of uplift W-SW of Cape Muroto which produces the tsunami itself, and roughly equal amounts of uplift and subsidence at Cape Muroto and the southern coast of Shikoku west of Cape Muroto, respectively. For constant slip on a thrust fault, the general pattern of vertical surface displacement consists of a maximum in subsidence above the down-dip end of the fault, with vertical deformation switching to uplift which increases monotonically as the up-dip end of the fault is approached (see, e.g., Savage (1983)). If fault slip producing the uplift observed at Cape Muroto $(2 \mathrm{~m}$ and $1 \mathrm{~m}$ for the 1707 and 1946 earthquakes, respectively) were confined to the plate boundary, and this uplift continued monotonically from Muroto to somewhere near the trough axis, the resulting volume of uplift would, evidently, produce a tsunami larger than is observed. Hence, the fault slip must have decreased some $100 \mathrm{~km}$ from the trough axis.

This decrease in slip could be achieved in either (or both) of two ways. In the case that slip occurs only on the plate 


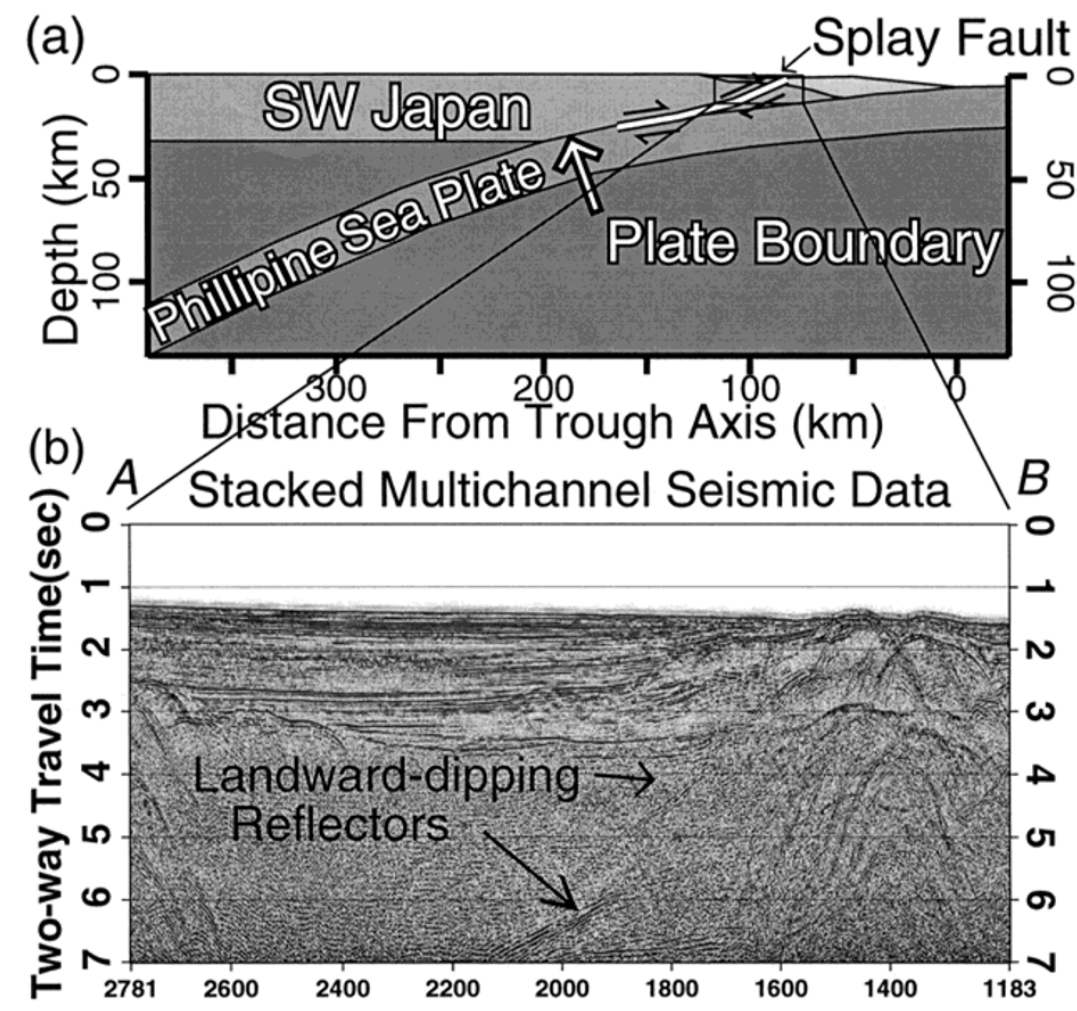

Fig. 2. (a) A cross-section of the splay fault model of Cummins and Kaneda (2000), superposed on a model for subsurface structure obtained from Kodaira et al. (2000). (b) multichannel seismic data collected by the Japan National Oil Corporation. The position of this section is indicated as the line A-B in Figs. 1(a)-(b), and it's cross-sectional position relative to Fig. 2(a) is roughly indicated.

boundary, it must undergo a substantial decrease at around $100 \mathrm{~km}$ from the trough axis, as in the model of Tanioka and Satake (2001) for the 1946 earthquake. This leaves the question open as to why such a decrease in slip would occur; the thermal modeling results of Hyndman et al. (1995) and Wang et al. (1995) suggest that the plate boundary should exhibit stick-slip frictional behavior to within a few tens of $\mathrm{km}$ of the trough axis. (note that Aida's (1981) model for the 1946 earthquake does have constant slip over this range, but does not attempt to resolve the down-sip slip distribution, as Tanioka and Satake (2001) do). Alternatively, the slip could have occurred not on the plate boundary, but instead on the type of splay fault considered here. In this case the decrease in slip $100 \mathrm{~km}$ landward of the trough is simply due to termination of the fault there.

As pointed out by Cummins and Kaneda (2000), the plate boundary and splay fault models for slip in the western part of the Nankai Trough are both extreme cases, and in reality an earthquake may involve slip partitioning over the plate boundary and one or more splay faults. It may be, however, that such splay faults do not have a clear geologic expression at the surface, but instead terminate at the base of the relatively weak accretionary prism. If the shallower part of the accretionary prism is capable of relieving stress by mechanisms such as creep or slip on secondary fractures, thrust faults beneath it can slip without reaching the surface (Stein and King, 1984). The cross-sectional geometry for the splay fault of Cummins and Kaneda (2000) is illustrated in Fig. 2(a). Although difficult to discern due to the scale of the figure, this fault actually terminates at the base of the accretionary prism, as required by Cummins and Kaneda (2000) in order to produce the broad uplift pattern evident in the tsunami inversion results of Tanioka and Satake (2001). Some evidence that such faults may actually exist can be seen in sections of multichannel seismic data collected and processed by the Japan National Oil Corporation. Two of the profiles which cross the region of interest reveal the top edges of landward-dipping, linear reflectors which could be interpreted as thrust faults beneath the accretionary prism in the Tosa Basin, one of which is shown in Fig. 2(b). Unfortunately, what the dip angles of these features may be, and whether they can be interpreted as a single, connected fault, cannot be ascertained from the stacked sections. We suggest that these may represent one or more active thrust faults which extend to the plate boundary at depth. According to the above discussion, thrust on such faults is consistent with the surface deformation inferred from modeling the tsunamis of the 1707 and 1946 earthquakes. In the next section we consider what effect slip on such faults may have on shear stress acting on the megathrust.

\section{Splay Fault Slip and Megathrust Stress}

To the extent that the stress field in the Nankai Trough forearc is constrained by earthquake focal mechanisms, the principle compressive stress is thought to be roughly parallel to the trough strike, while the least compressive stress is normal to the trough axis (Kagami et al., 1983; Seno, 1999; Wang and He, 1999). However, as explained by Wang and He (1999), this stress state does not prevail in the weaker accretionary prism, where plastic failure occurs as a result of 
(a)

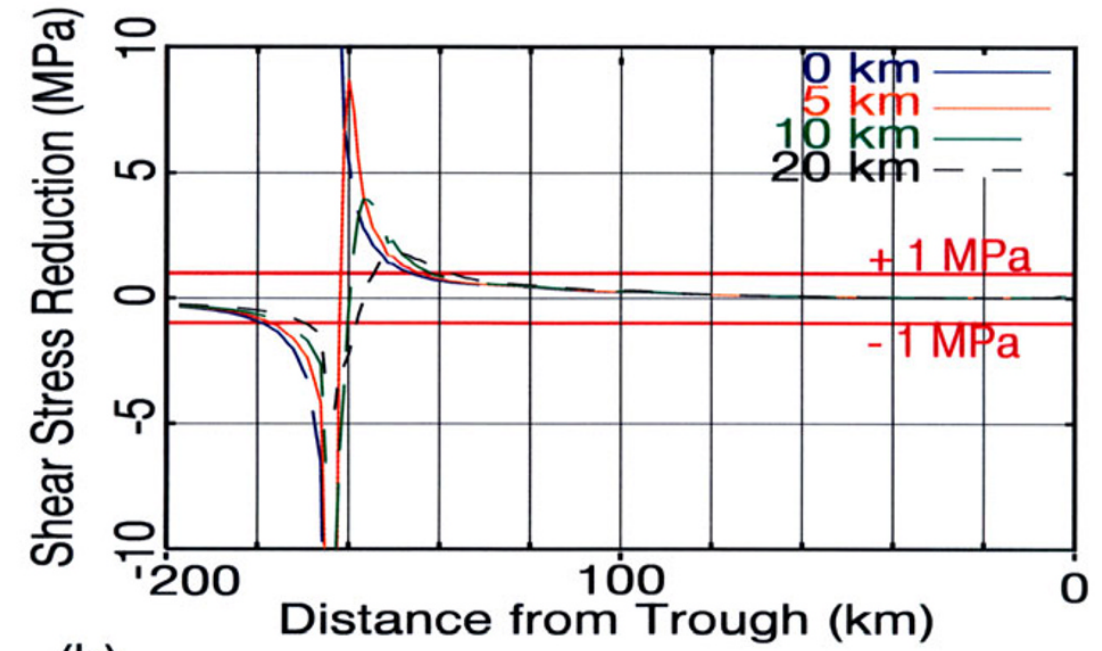

(b)

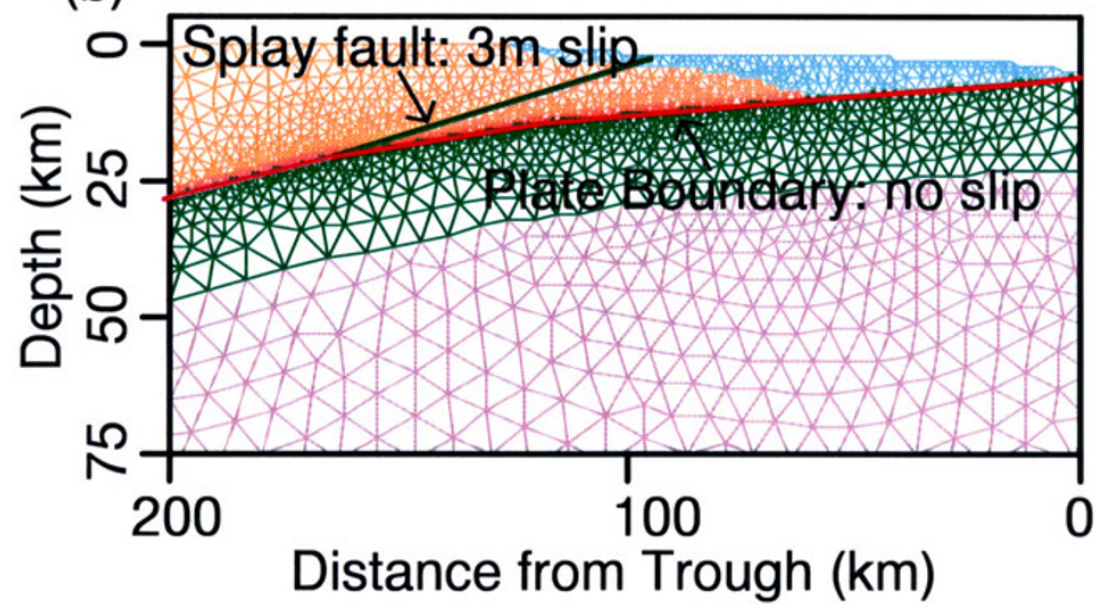

Fig. 3. (a) Results for the calculated shear stress reduction on the megathrust due to $3 \mathrm{~m}$ slip on the splay fault in (b). Four cases are presented, in which slip increases from 0 at the base of the splay fault to $3 \mathrm{~m}$ over an along-fault distance of $0,5,10$ and $20 \mathrm{~km}$. (b) The finite element mesh used for the calculation in (a).

margin-normal compression. In any case, due to the very low seismicity west of Cape Muroto the stress field there is poorly constrained. Also, the strike of the splay fault considered in the previous section is neither parallel nor normal to the trough axis. Hence, apart from the fact that the stress field is compressive, it is difficult to say how favorably oriented the splay fault of Fig. 2(a) is, and what type of slip might be expected.

Instead we rely on the results of Cummins and Kaneda (2000) suggesting that up to $3 \mathrm{~m}$ of thrust slip may have occurred on the splay fault during the 1946 earthquake, and consider how this slip might interact with stress on the megathrust. To this end we have constructed a finite element model, a part of which is displayed in Fig. 3(b). The lateral boundaries of this model are taken at $400 \mathrm{~km}$ landward and 150 $\mathrm{km}$ seaward of the trough axis, and boundary conditions are applied such that the bottom grid point of each boundary is fixed while the rest of the boundary can slip in the vertical direction. The base of the model is taken at $400 \mathrm{~km}$ depth, where a boundary condition of free horizontal but zero vertical slip is applied. We checked that fixing these boundaries to have zero slip during the calculation had little effect on the calculated stresses, so we believe that our results are not sensitive to these boundary conditions.

The plate boundary and elastic constants of our model are inferred from the results of Kodaira et al. (2000), who recently performed a wide-angle ocean-bottom seismic survey in this part of the Nankai Trough. The splay fault is a slightly simplified version of that used in Cummins and Kaneda (2000); while their splay fault extended over 3 segments having 30, 15 and 7.5 degrees dip, the splay fault in our finite element model is situated similarly but is a single linear segment with 17 degrees dip. Since the detailed geometry of the splay fault is not well determined, this simplified model seems adequate. We note that in the shallowest part of the model, where the fault penetrates the accretionary prism, we enforced a condition of zero shear stress, consistent with the assumption that stress only accumulates in the stronger material of the underlying island arc crust.

Our finite element implementation uses paired nodes on each fault to represent two surfaces. Each pair of nodes shares the same position, but one corresponds to the hanging 
wall of the fault while the other corresponds to the foot wall. A displacement discontinuity equal to the fault slip is enforced using the Lagrange multiplier technique (Zienkiewicz and Taylor, 1997). We use this technique to prescribe $3 \mathrm{~m}$ of thrust slip on the splay fault, as well as zero slip on the megathrust. This latter condition, which is equivalent to having no fault at all, is enforced so that we can take advantage of the fact that the Lagrange multiplier used to enforce the slip condition assumes the numerical value of the traction on the interface required to maintain the slip (Zienkiewicz and Taylor, 1997). Use of the finite element method for the calculation presented here instead of, for example, the analytic solution of Okada (1992) for fault slip in a homogeneous halfspace, in principle allows us to use arbitrary fault and free surface geometry as well as spatial variation in elastic constants. However, it seems likely to us that the same conclusions would have been reached had a simpler formulation been used.

The change in shear stress on the megathrust due to $3 \mathrm{~m}$ of thrust displacement on the splay fault is illustrated in Fig. 3(b). We display these results for 4 different cases: one in which splay fault displacement terminates abruptly where the splay fault intersects the megathrust, and cases in which this displacement decreases smoothly from $3 \mathrm{~m}$ to zero over intervals of 5, 10 and $20 \mathrm{~km}$ distance from this intersection point. All four of these calculations result in a decrease in shear stress (i.e., a change in shear stress which is opposite in sign to the shear stress accumulated due to plate subduction) along the megathrust seaward of the base of the splay fault. Along the megathrust landward of this point there is always an increase in shear stress. The first case results in a stress singularity, appearing in our results as very high stresses of opposite sign on either side of the base of the splay fault. As the zone over which slip increases from zero to $3 \mathrm{~m}$ lengthens from 0 to $20 \mathrm{~km}$, the effect of this singularity is smoothed out, and the positive lobe of stress reduction on the megathrust shifts seaward of the base of the splay fault.

Two scenarios can be considered from the result displayed in Fig. 3. On the one hand, if rupture occurs at depth landward of the splay fault's intersection with the megathrust, a stress concentration opposite to the sense of that shown in Fig. 3(a) will develop at the intersection point. Figure 3 then shows that slip on the splay thrust will relieve this stress concentration, resulting in reduced "loading" of the megathrust seaward of the intersection point. As a consequence slip on the seaward portion of the megathrust will be reduced or even arrested, and in this sense the earthquake rupture area in the up-dip direction would be effectively shortened due to slip on the splay fault.

On the other hand, if splay fault slip occurred independently of megathrust slip, the effect would be loading of the megathrust landward and reduction of shear stress on the megathrust seaward of the splay fault. Depending on the frictional properties of the plate boundary, this could result in effectively shortening the recurrence interval for slip landward of the splay fault, while lengthening the interval for slip seaward of the splay fault.

In either case, the calculation presented here shows that $3 \mathrm{~m}$ of splay fault slip can lead to shear stress changes of the order of several MPa along the megathrust near the base of the seismogenic zone. The absolute shear stress along the plate boundary in the Nankai Trough is thought to have a maximum of only $17 \mathrm{MPa}$ near this down-dip limit (Wang and He, 1999). This represents the shear stress averaged over the temporal variations associated with the earthquake cycle. While the amplitude of the temporal variation in stress could be double this, it could also be as small as the 3.3 MPa stress drop estimated for the 1946 Nankai and 1944 Tonankai earthquakes by Kanamori (1972). In any case, the shear stress perturbation due to the splay fault slip calculated here seems large enough to contribute some variability to megathrust earthquake occurrence.

\section{Conclusions}

In this paper we have attempted to call attention to the potential importance of splay faults in influencing the behavior of megathrust earthquakes in the Nankai Trough. We have shown, through examination of the tsunami modeling results of previous studies, that such slip may have occurred on a particular segment of the Nankai Trough just west of Cape Muroto during the earthquakes of 1707 and 1946. The evidence for this consists of a maximum in uplift off Cape Muroto about $100 \mathrm{~km}$ from the trough axis. We think the persistence of this feature in the tsunami modeling results of various authors is an indication of some along-strike change in the rupture character of megathrust earthquakes that should be explained if we are to achieve an improved understanding of this important seismogenic zone. Splay fault slip is one possible explanation, but there are other possibilities, such as a change in frictional properties on the up-dip portion of the plate boundary.

The resolution of Aida's (1981) models for earthquake slip distributions in the Nankai Trough, particularly for older earthquakes like the 1707 event, is open to question. Also, Aida's (1981) models for the 1854 and 1946 earthquakes do have slip extending to near the trench axis, which is not indicative of splay fault slip. It seems likely, then, that some earthquakes may rupture the plate boundary and not the splay fault off Shikoku, and it also seems possible that some earthquakes may rupture both, with the partitioning of slip along the splay fault and megathrust varying for each earthquake. Here we only suggest that substantial slip on one or more splay faults off Cape Muroto seems to have occurred for at least one (the 1946 event) and possible two (1946 and 1707 events) earthquakes.

In support of the splay fault hypothesis, we found intriguing evidence for the existence of splay faults in the form of landward-dipping reflectors evident in record sections of multichannel seismic data from the Tosa Basin. Although more concrete conclusions regarding the nature of these reflectors will require further processing of the data, their location in precisely the area required to match the tsunami results suggests that they may be associated with megathrust earthquakes. Also, Cummins and Kaneda (2000) note two submersible observations of biological communities which were made roughly along the strike of their proposed fault. Such chemosynthetic benthic colonies serve as markers for vents of deeply-sourced fluid from accretionary prisms, and for the more consolidated, landward portion of the accretionary prism such fluid flow tends to be concentrated along faults. 
Finally, we performed a simple calculation demonstrating that thrust slip on the type of splay fault proposed here for the Nankai Trough will result in reduced shear stress on the portion of the megathrust seaward of the base of the splay fault. For the $3 \mathrm{~m}$ slip suggested in Cummins and Kaneda (2000), this reduction in shear stress is of the order of several MPa very near the base of the fault, and can result in a shear stress reduction of $1 \mathrm{MPa}$ distributed over a $20 \mathrm{~km}$ length of the megathrust seaward of this point. While it is not clear what stress amplitude is associated with the variations in shear stress during the course of the earthquake cycle, the modeling results of Wang and He (1999) argue for low absolute shear stress (i.e., tens of MPa), while Kanamori's (1972) estimate of stress drop for the the 1944 and 1946 earthquakes is only $3.3 \mathrm{MPa}$. Thus, it seems that the $1 \mathrm{MPa}$ reduction in shear stress obtained here is potentially significant. This stress reduction could result in either reduced slip along the megathrust seaward of the splay fault, as is suggested by the tsunami modeling results of other authors, or it could lengthen the recurrence time for future earthquake slip to occur there.

Acknowledgments. We thank Kelin Wang, Takeshi Sagiya and an anonymous reviewer for their helpful comments. We are also grateful to the Japan National Oil Corporation for providing us with the mutlichannel seismic section in Fig. 2(b).

\section{References}

Aida, I., Numerical experiments of historical tsunamis generated off the coast of the Tokaido district, Bull. Earthq. Res. Inst., 56, 715-730, 1981 (in Japanese).

Ando, M., Source mechanisms and tectonic significance of historical earthquakes along the Nankai Trough, Japan, Tectonophys., 27, 119-140, 1975.

Clarke, S. H. and G. A. Carver, Late Holocene Tectonics and paleoseismicity, southern Cascadia subduction zone, Science, 255, 188-192, 1992.

Cummins, P. R. and Y. Kaneda, Possible splay fault slip during the 1946 Nankai earthquake, Geophys. Res. Lett., 27, 2725-2728, 2000.
Hyndman, R. D., K. Wang, and M. Yamano, Thermal constraints on the seismogenic portion of the southwestern Japan subduction thrust, J. Geophys. Res., 100, 15,373-15,392, 1995.

Kagami, H., K. Shiono, and A. Taira, Plate subduction and formation of the accretionary complex in the Nankai Trough, Kagaku, 53, 429-438, 1983 (in Japanese).

Kanamori, H., Tectonic implications of the 1944 Tonankai and 1946 Nankaido earthquakes, Phys. Earth Planet. Inter., 5, 129-139, 1972.

Kodaira, S., N. Takahashi, J. Park, K. Mochizuki, M. Shinohara, and S. Kimura, The western Nankai Trough seismogenic zone: Result from wide-angle ocean-bottom seismographic survey, J. Geophys. Res., 105, 5887-5905, 2000.

McCaffrey, R., On the role of the upper plate in great subduction zone earthquakes, J. Geophys. Res., 98, 11,953-11,966, 1993.

Okada, Y., Internal deformation due to shear and tensile faults in a halfspace, Bull. Seismol. Soc. Am., 82, 1018-1040, 1992.

Plafker, G., Alaskan earthquake of 1964 and Chilean earthquake of 1960: implications for arc tectonics, J. Geophys. Res., 77, 901-923, 1972.

Sagiya, T. and W. Thatcher, Coseismic slip resolution along a plate boundary megathrust: The Nankai Trough, southwest Japan, J. Geophys. Res., 104, 1111-1129, 1999

Savage, J. C., A dislocation model of strain accumulation and release at a subduction zone, J. Geophys. Res., 88, 4984-4996, 1983.

Seno, T., Syntheses of the regional stress fields of the Japanese islands, The Island Arc, 8, 66-79, 1999.

Stein, R. S. and G. C. P. King, Seismic potential revealed by surface folding: 1983 Coalinga, California, earthquake, Science, 224, 869-872, 1984.

Sugiyama, Y., Neotectonics of Southwest Japan due to the right-oblique subduction of the Philippine Sea plate, Geofis. Int., 33, 53-76, 1994.

Tanioka, Y. and K. Satake, Coseismic slip distribution of the 1946 Nankai earthquake and aseismic slips caused by the earthquake, Earth Planets Space, 53, this issue, 235-241, 2001.

Wang, K. and J. He, Mechanics of low-stress forearcs: Nankai and Cascadia, J. Geophys. Res., 104, 15,191-15,205, 1999.

Wang, K., R. D. Hyndman, and M. Yamano, Thermal regime of the southwest Japan subduction zone: effects of age history of the subducting plate, Tectonophys., 248, 53-69, 1995.

Zienkiewicz, O. C. and R. L. Taylor, in The Finite Element Method, 648 pp., McGraw-Hill, London, 1997.

P. R. Cummins (e-mail: cummins@jamstec.go.jp), T. Hori, and Y. Kaneda 